\title{
REFLEXOS DA NOVA CLT PARA EMPREGADOS E EMPREGADORES - DIREITO DO TRABALHO - ALTERAÇÕES DA LEI 13.467/2017
}

\author{
Fernanda Maria Lacerda Oliveira, Rafael Correia Claro, Marcio Franca Teixeira \\ Universidade do Oeste Paulista - UNOESTE, curso de Direito, Presidente Prudente, SP.
}

\begin{abstract}
RESUMO
A ideia principal deste material consiste em demonstrar que as alterações da reforma nas leis que regulam as normas trabalhistas representarão para os empregados e seus respectivos empregadores. Iremos discorrer somente sobre as principais alterações, as mais impactantes no dia a dia da relação de emprego, já que a reforma alterou em torno de cem artigos da CLT. Trataremos de forma breve uma vez que não temos o socorro da jurisprudência, e pouquíssima doutrina a respeito. Tendo em vista o principio da proteção e da dignidade da pessoa humana, que são os principais princípios constitucionais que regem o direito do trabalho, para se chegar a um maior conhecimento de todos que participam dessa relação jurídica.
\end{abstract}

\begin{abstract}
The main idea of this material is to demonstrate that the changes in the reform in the laws that regulate labor standards will represent for employees and their respective employers. We will only discuss the main changes, the most striking in the day employment relationship, since the reform changed around one hundred CLT articles. We will deal briefly since we do not have the help of jurisprudence, and very little doctrine about it. In view of the principle of the protection and dignity of the human person, which are the principal constitutional principles governing labor law, in order to reach a greater knowledge of all those who participate in this legal relationship.
\end{abstract}

\section{INTRODUÇÃO}

A consolidação das leis do trabalho incialmente contendo um total de 922 artigos sofreu inúmeras alterações, além dos dispositivos acrescidos pela Constituição Federal de 1988, que é nossa lei maior. As alterações, também conhecida como modernização das leis do trabalho veio atualizar a relação de emprego da nossa sociedade atual. A reforma segundo o Governo é uma forma de modernizar a lei, flexibilizando a legislação vigente para facilitar as relações de emprego.

\section{OS OBJETIVOS PRINCIPAIS DA PESQUISA SÃO:}

1) Comparar a alteração do direito material.

2) Demonstrar o impacto na relação de emprego.

\section{METODOLOGIA}

Pesquisa bibliográfica, textos legais e sites oficiais.

\section{OS PRINCIPAIS PONTOS DA ALTERAÇÃO TRABALHISTA}




\section{HORAS IN ITINERE}

Hora in itinere consiste no lapso de tempo em que o trabalhador se locomove casatrabalho e vice versa ao qual não é computado na jornada de trabalho, salvo quando o local de trabalho se trata de um lugar ermo e de difícil acesso e não tendo serviço de transporte público regular, neste caso o empregador deve fornecer um meio de transporte, ainda sim esse período é computado na jornada do empregado, assegurado no §2ㅇ do artigo 58 da CLT e pela súmula 90 do TST. Mas a alteração da lei trouxe uma imensa mudança neste instituto. Não há mais o pagamento de horas extras durante o período de trajeto que o empregado se desprende casa-trabalho e viceversa mesmo se tratando de local de difícil acesso e sem a prestação de transporte público regular.

\section{LEI ANTERIOR:}

Art. 58 (...): $\S 2^{\circ} \mathrm{O}$ tempo despendido pelo empregado até o local de trabalho e para o seu retorno, por qualquer meio de transporte, não será computado na jornada de trabalho, salvo quando, tratando-se de local de difícil acesso ou não servido por transporte público, o empregador fornecer a condução.

\section{NOVA LEI:}

Art. 58 (...): $\S 2^{\circ} \mathrm{O}$ tempo despendido pelo empregado desde a sua residência até a efetiva ocupação do posto de trabalho e para o seu retorno, caminhando ou por qualquer meio de transporte, inclusive o fornecido pelo empregador, não será computado na jornada de trabalho, por não ser tempo à disposição do empregador.

\section{REFLEXOS DA ALTERAÇÃO DA LEI}

É nítida a economia que o empregador terá em função do não pagamento das horas in itinere. Já o empregado não terá computado a sua jornada de trabalho as horas perdidas durante o trajeto de trabalho, o prejuízo será suportado somente por este, uma vez que, ou ele perderá o poder econômico vindo do recebimento das horas extras in itinere ou ficará menos tempo na esfera familiar, pois terá que cumprir toda a jornada somada a demora da chegada ao local do trabalho.

\section{FÉRIAS INDIVIDUAIS}

Férias é um período de descanso remunerado que o empregado adquire depois de um ano de labor que tem por finalidade que o empregado possa descansar psicologicamente e fisicamente. $\mathrm{O}$ artigo 134 da CLT determina que o descanso das férias seja em apenas um período de 30 dias, salvo situações especiais que possibilita que seja dividido em até dois períodos desde que um deles não seja menor que dez dias corridos. Com a alteração da lei o empregador poderá dividir as férias em até períodos, sendo que um deve ter pelo menos quatorze dias descansados não pode ser menor que cinco dias descansados, desde que o empregado aceite dessa forma.

\section{LEI ANTERIOR:}

Art. 134 (...): $\S 1^{\circ}$ Somente em casos excepcionais serão as férias concedidas em 2 (dois), períodos, um dos quais não poderá ser inferior a 10 (dez), dias corridos. $\S 2^{\circ}$ Aos menores de 18 (dezoito), anos e aos maiores de 50 (cinquenta), anos de idade, as férias serão sempre concedidas de uma só vez.

\section{NOVA LEI:}

Art. 134 (....): $\S 1^{\circ}$ Desde que haja concordância do empregado, as férias poderão ser usufruídas em até três períodos, sendo que um deles não poderá ser inferior a quatorze dias 
corridos e os demais não poderão ser inferiores há cinco dias corridos, cada um. $\S 2^{\circ}$ (Revogado). $\S$ $3^{\circ}$ É vedado o início das férias no período de dois dias que antecede feriado ou dia de repouso semanal remunerado.

\section{REFLEXOS DA ALTERAÇÃO DA LEI:}

Para o empregador terá o benefício de organização desses períodos e sentirá menos efeitos com a ausência do colaborador no seu respectivo setor de trabalho. Já para o empregado dependerá de cada situação específica, sendo que para uns é vantajoso descansar vários períodos no ano e para outros haverá desvantagem, pois os trinta dias de descanso é fundamental para se restabelecer sua energia para o trabalho.

\section{TRABALHO DA MULHER EM CONDIÇÕES INSALUBRE}

O artigo 394-A vem garantir a empregada gestante ou lactante o afastamento de suas atividades laborais quando o local e trabalho forem insalubres, devendo exercer atividade em outra função que não haja exposição a riscos mais gravosos a saúde. Com a modificação da legislação é entendido que a mulher gestante ou lactante que trabalhe em local insalubre considerado de grau mínimo ou médio não haverá a necessidade de afastamento de sua função, somente quando a insalubridade tiver em seu grau máximo a mulher deverá ser afastada de sua função.

\section{LEI ANTERIOR:}

Art. 394-A. A empregada gestante ou lactante será afastada, enquanto durar a gestação e a lactação, de quaisquer atividades, operações ou locais insalubres, devendo exercer suas atividades em local salubre. Parágrafo único. (VETADO).

\section{NOVA LEI:}

Art. 394-A. Sem prejuízo de sua remuneração, nesta incluído o valor do adicional de insalubridade, a empregada deverá ser afastada de: I - atividades consideradas insalubres em grau máximo, enquanto durar a gestação; II - atividades consideradas insalubres em grau médio ou mínimo, quando apresentar atestado de saúde, emitido por médico de confiança da mulher, que recomende o afastamento durante a gestação; III - atividades consideradas insalubres em qualquer grau, quando apresentar atestado de saúde, emitido por médico de confiança da mulher, que recomende o afastamento durante a lactação. $\S 1^{\circ} \ldots \S 2^{\circ}$ Cabe à empresa pagar o adicional de insalubridade à gestante ou à lactante, efetivando-se a compensação, observado o disposto no art. $\underline{248}$ da Constituição Federal, por ocasião do recolhimento das contribuições incidentes sobre a folha de salários e demais rendimentos pagos ou creditados, a qualquer título, à pessoa física que Ihe preste serviço. $\$ \mathbf{3}^{\circ}$ Quando não for possível que a gestante ou a lactante afastada nos termos do caput deste artigo exerça suas atividades em local salubre na empresa, a hipótese será considerada como gravidez de risco e ensejará a percepção de salário-maternidade, nos termos da Lei $n^{\circ} 8.213$, de 24 de julho de 1991, durante todo o período de afastamento.

\section{REFLEXOS DA ALTERAÇÃO DA LEI:}

A empresa deve atentar-se para controlar devidamente os atestados médicos fornecidos pela gestante ou lactante, quando grau mínimo ou médio de insalubridade. Quando grau máximo o afastamento da atividade da empregada deve ser o mais rápido possível, logo após o conhecimento da gravidez. Para a trabalhadora deve atentar se junto ao seu médico para elaboração de atestado que a proíba ou não de exercer sua função com as condições de insalubridade da empresa. 


\section{TRABALHO INTERMITENTE}

A CLT não prevê regulamentação para o trabalho intermitente. A Lei trouxe regulamentação para essa modalidade de trabalho. Sem definição de uma carga horária mínima, com subordinação, não contínua, com variação de prestação de serviços.

\section{LEI ANTERIOR:}

Não existia essa modalidade

\section{NOVA LEI:}

Art. 443. O contrato individual de trabalho poderá ser acordado tácita ou expressamente, verbalmente ou por escrito, por prazo determinado ou indeterminado, ou para prestação de trabalho intermitente. $\$ \mathbf{3}^{\circ}$ Considera-se como intermitente o contrato de trabalho no qual a prestação de serviços, com subordinação, não é contínua, ocorrendo com alternância de períodos de prestação de serviços e de inatividade, determinados em horas, dias ou meses, independentemente do tipo de atividade do empregado e do empregador, exceto para os aeronautas, regidos por legislação própria." (NR). Art. 452-A: O contrato de trabalho intermitente deve ser celebrado por escrito e deve conter especificamente o valor da hora de trabalho, que não pode ser inferior ao valor horário do salário mínimo ou àquele devido aos demais empregados do estabelecimento que exerçam a mesma função em contrato intermitente ou não. $\S 1^{\circ}$ : 0 empregador convocará, por qualquer meio de comunicação eficaz, para a prestação de serviços, informando qual será a jornada, com, pelo menos, três dias corridos de antecedência. § $2^{\circ}$ : Recebida a convocação, o empregado terá o prazo de um dia útil para responder ao chamado, presumindo-se, no silêncio, a recusa. $\S 3^{\circ}$ : A recusa da oferta não descaracteriza a subordinação para fins do contrato de trabalho intermitente. $\S 4^{\circ}$ : Aceita a oferta para o comparecimento ao trabalho, a parte que descumprir, sem justo motivo, pagará à outra parte, no prazo de trinta dias, multa de $50 \%$ (cinquenta por cento) da remuneração que seria devida, permitida a compensação em igual prazo. $\$ 5^{\circ}$ : O período de inatividade não será considerado tempo à disposição do empregador, podendo o trabalhador prestar serviços a outros contratantes. $\S 6^{\circ}$ : Ao final de cada período de prestação de serviço, o empregado receberá o pagamento imediato das seguintes parcelas: I - remuneração; II - férias proporcionais com acréscimo de um terço; III - décimo terceiro salário proporcional; IV - repouso semanal remunerado; e $\mathrm{V}$ - adicionais legais. $\S 7^{\circ}$ : $\mathrm{O}$ recibo de pagamento deverá conter a discriminação dos valores pagos relativos a cada uma das parcelas referidas no $\S 6^{\circ}$ deste artigo. $\S 8^{\circ}$ : O empregador efetuará o recolhimento da contribuição previdenciária e o depósito do Fundo de Garantia do Tempo de Serviço, na forma da lei, com base nos valores pagos no período mensal e fornecerá ao empregado comprovante do cumprimento dessas obrigações. $\S 9^{\circ}$ : A cada doze meses, o empregado adquire direito a usufruir, nos doze meses subsequentes, um mês de férias, período no qual não poderá ser convocado para prestar serviços pelo mesmo empregador."

\section{REFLEXOS DA ALTERAÇÃO DA LEI:}

Para o empregador é a possibilidade de contratação de trabalhadores apenas para atender uma demanda sazonal. Para o trabalhador a possibilidade de ter vários contratos ao mesmo tempo, mantendo seus direitos como: férias, abono natalino (13 salário), adicionais e repouso semanal remunerado (RSR).

\section{CONCLUSÃO}

Diante de todos esses pontos que foram expostos neste trabalho, concluímos que o texto da reforma trabalhista que foi sancionada pelo presidente Temer em comparação à legislação anterior, é percebido que houve diminuição da proteção ao trabalhador e um aumento da carga 
de trabalho, ao passo que trabalhador para ter fonte de renda para sua sobrevivência, amargará tais mudanças. A reforma não representa um equilíbrio entre as partes, claramente visível uma classe se favorecendo sobre outra, aumentando ainda mais a hipossuficiência do trabalhador.

\section{REFERÊNCIAS BIBLIOGRÁFICAS}

http://www.planalto.gov.br/ccivil 03/decreto-lei/Del5452.htm

http://www.planalto.gov.br/ccivil 03/ ato2015-2018/2017/lei/L13467.htm

http://g1.globo.com/economia/noticia/desemprego-fica-em-133-no-trimestre-encerrado-em$\underline{\text { maio.ghtml }}$ 